\title{
HUBUNGAN STRUKTUR ORGANISASI DENGAN EFEKTIFITAS KERJA PEGAWAI NEGERI SIPIL
}

\author{
Zain Noktah Asli \\ Email: zain.noktahaslie@gmail.com
}

\author{
Universitas Islam Kalimantan (UNISKA) MAB Banjarmasin
}

\begin{abstract}
This study aims about relationship of organization structure with job effectivity. The method is explanatory survey research so date was got based on sample form all of population. Number of sample are 34 people which was got random on simple random. To know exist or not relationship used statistic test of Spearman Rank Correlation Coefficient.

Based on analysis result can be explain, that the effectivity grade of officer work on education and culture service look good. Accourding to three indicator which was measured is job productivity, job efficiency, and job satisfication and follow in all of responden opinion look good. This means job effectivity of officer which was not optimal is causal from organization structure was not applicated exactly yet.

From aspect for organization structure less support to job effectivity lock by share job which less with need of officer and the deparity treatment make the officer apt to character not constructive. Although in share of job as rule accourding to normative rule and as to organization structure but implementative only take the name of organization personnel, and the irony is not all of officer understand what the job description.
\end{abstract}

Keywords: Organization structure and job effectivity

\section{PENDAHULUAN}

Pada era globalisasi tuntutan terhadap cara kerja dengan menggunakan teknologi tinggi, dan pengaruh lingkungan luar yang kuat, mendorong organisasi untuk mampu beradaptasi dengan lingkungan tersebut, sehingga mampu menghasilkan efektifitas kerja yang tinggi.

Gibson, (2007) mengatakan, bahwa struktur keorganisasian memudahkan tercapainya tujuan organisasi. Asumsi ini tidak lepas 
dari keterlibatan pemegang otoritas (manajer), karena kegiatan organisasi yang terstruktur memerlukan kehadiran pemimpin yang mampu mendayagunakan sumber daya organisasi secara efektif dan efisien. Namun tidak semua pimpinan mampu merumuskan struktur yang relevan dengan tujuan organisasi sehingga terjadinya kegagalan dalam mencapai tujuan. Walaupun struktur organisasi menurut pandangan pada ahli telah memberikan kontribusi positif terhadap efektifitas kerja pegawai akan tetapi hal tersebut tidak akan berhasil secara efektif jika tidak dibarengi dengan kualitas kepemimpinan.

Cakupan struktur organisasi meliputi (Gibson, 2007) : pembagian pekerjaan,

desentraliasi kewenangan, rentang kendali, (4) formalisasi, dan (5) departementasi.
Berdasarkan penjelasan di atas perlu dikaji secara mendalam dengan maksud agar pencapaian tujuan organisasi lebih efektif dan efisien. Struktur organisasi yang bagaimana yang dapat memberikan kontribusi berarti bagi efektifitas kerja. Untuk maksud tersebut perlu dilakukannya suatu penelitian lapangan, agar problema organisasi yang bermuara pada tujuan organisasi secara baik dan benar dapat dicapai.

\section{Perumusan Masalah}

Hasil observasi pada objek penelitian menunjukkan bahwa yang menjadi pernyataan masalah (problem statement) tingkat efektifitas kerja belum sesuai dengan yang diharapkan. Hal tersebut disebabkan : (1) adanya perbedaan antara analisa pekerjaan dengan beban pekerjaan. (2) adanya beberapa pekerjaan yang mengerjakan berbagai jenis pekerjaan yang tidak sesuai dengan uraian kerjanya. (3) adanya 
pekerjaan yang memikul tugas dan tanggung jawab yang tidak sesuai dengan kapasitas pekerja.

Berdasarkan pernyataan masalah tersebut, maka tujuan penelitian ini adalah untuk menguji dan mengkaji hubungan antara struktur organisasi dengan efektifitas kerja pegawai pada Dinas Pendidikan dan Kebudayaan Kota Banjarmasin.

Hasil penelitian ini diharapkan dapat berguna untuk pengembangan ilmu manajemen,khususnya memperkaya pandangan ilmiah di bidang studi ilmu manajemen sumber daya manusia. Selain itu juga dapat menjadi bahan masukan bagi lembaga yang bersangkutan sebagai bahan pertimbangan dalam pengambilan keputusan dimasa yang akan datang

\section{METODE PENELITIAN}

Penelitian ini dilakukan pada

Dinas Pendidikan dan Kebudayaan Kota Banjarmasin. Pemilihan lokasi dilakukan atas pertimbangan sebagai berikut : (1) Untuk mengetahui fenomena yang terjadi dari sifat populasi terhadap faktor struktur organisasi dan efektivitas kerja pegawai, dan (2) Informasi data di objek penelitian mudah diperoleh.

\section{Jenis Penelitian}

Penelitian yang digunakan adalah metode survei dengan analisis diskriptif dan verikatif. Metode survei adalah suatu penelitian dengan alat pengambilan datanya dari sejumlah sampel yang diambil dari populasi dan menggunakan kuisioner. Sedangkan analisis diskriptif adalah menggambarkan fenomenafenomena yang terjadi terutama yang berkaitan dengan data variabel pendidikan dan pelatihan dan variabel efektivitas kerja pegawai.

Populasi dan Sampel 
Objek penelitian ini adalah pada Kantor Dinas Pendidikan dan Kebudayaan Kota Banjarmasin. Populasi penelitian adalah seluruh pegawai negeri sipil yang ada di lembaga tersebut, yaitu berjumlah 134 orang.

Kemudian, untuk menentukan besarnya sampel dalam penelitian ini digunakan berdasarkan pendapat Yama (Singarimbun, 2006), dengan rumus sebagai berikut:

Daerah pengambilan sampel, digunakan presisi sebesar $15 \%$, jika dilakukah perhitungan dengan menggunakan rumus tersebut diperoleh nilai sebesar 34, sehingga pengambilan sampel sebanyak 34 orang, secara Simpel Random Sampling. Penentukan besarnya sampel secara alokasi proporsional diambil dengan rumus sebagai berikut:

$$
n=\frac{N}{N d^{2}+1}
$$

$$
n_{i}=\frac{N_{i}}{N} \times n
$$

\section{Definisi Operasional Variabel}

Untuk menghindarkan adanya penafsiran yang berbeda tentang konsep struktur organisasi dan produktivitas hubungan, maka perlu dibuat definisi operasional variabel, yaitu :

1. Variabel struktur organisasi adalah kerangka dasar menyeluruh yang mempersatukan pola-pola hubungan, peran dan aturan interaksi diantara para personil yang terlibat dalam suatu organisasi dalam rangka pencapaian tujuan.

2. Efektivitas kerja adalah tingkat pencapaian sasaran yang didasarkan pada hasil kerja yang lebih baik, efisiensi waktu dan tenaga, dan kepuasan kerja yang didasarkan pada hasil yang dicapai. 


\section{Operasional Variabel}

A. Variabel Struktur Organisasi diukur melalui indikator sebagai berikut:

1. Pembagian pekerjaan
a. Adanya alokasi personil
b. Adanya alokasi tugas
c. Ketersediaan informasi tentang program

2. Desentralisasi kewenangan
a. Keterlibatan
dalam pengambilan keputusan
b. Keterlibatan
dalam perencanaan

3. Formalisasi
a. Prosedur kerja
b. fleksibelitas operasional kerja

4. Koordinasi
a. Keterpaduan personil dalam pelaksanaan tugas
b. Usaha pembuatan kesepakatan dengan pihak terkait
c. Tim kerja sama antar pihak terkait

B. Variabel Efektivitas Kerja Pegawai diukur melalui indikator sebagai berikut:

1. Produksi
a. Jumlah hasil kerja
b. Kualitas hasil kerja
c. Kemampuan menyelesaikan pekerjaan yang dibeban

d. Kemampuan untuk memperbaiki hasil kerja

2. Efisiensi
a. Waktu yang diperlukan untuk menyelesaikan pekerjaan
b. Jumlah tenaga kerja yang diperlukan untuk suatu pekerjaan

c. Kemampuan memanfaatkan sumber dana

d. Kemampuan untuk memanfaatkan sarana/prasarana

3. Kepuasan
a. Hasil kerja yang dicapai
b. Tugas yang dibebankan 
c. Kemampuan mengatasi masalah

d. Kualitas pekerjaan

\section{Teknik pengukuran data}

Di dalam penelitian terdapat beberapa alat pengukuran data yang biasa dipergunakan, antara lain dengan pengukuran skala nominal, ordinal, interval dan rasio. Sesuai gejala dikemukakan maka untuk pengukuran data yang digunakan adalah dengan skala ordinal yaitu suatu skala yang mengurutkan nilai/skor dari tingkatan paling rendah ke tingkat paling tinggi, dari suatu menurut atribut tertentu. Sugiono (2006) mengatakan mengukuran ordinal dapat menggunakan skala Likert yaitu tidak setuju ( 1 ), setuju (2) dan sangat setuju (3).

\section{Uji Hipotesis}

Alat analisis yang digunakan adalah dengan Uji Statistik Koefisien
Korelasi Rank Spearman, dengan rumus sebagai berikut:

$$
r_{s}=1-\frac{6 \sum_{i-1}^{N} d_{i}^{2}}{N_{3}-N}
$$

Apabila dalam pengolahan data terdapat skor yang sama atau ganda, maka uji statistik yang digunakan sebagai berikut:

$$
\begin{aligned}
\operatorname{Dimana}_{s}= & \frac{\sum X^{2}+\sum Y^{2}-\sum d_{i}^{2}}{2 \sqrt{\sum X^{2} \cdot \sum Y^{2}}} \\
& \sum Y^{2}=\frac{N^{3}-N-\sum T_{y}}{12} \\
& \sum X^{2}=\frac{N^{3}-N-\sum T_{x}}{12}
\end{aligned}
$$

Untuk faktor korelasi jumlah kuadrat himpunan yang berangka sama pada $X$ dan $Y$, dengan rumus sebagai berikut:

$$
\begin{aligned}
& \mathrm{T}=\mathrm{t}^{3}-\mathrm{t} \\
& \text { Sedangkan }
\end{aligned}
$$

untuk mengetahui signifikansi hubungan dari kedua $t=r_{1} \frac{\text { arabed }}{1-R^{2}}$ tersebut digunakan uji $\mathrm{t}^{1}{ }^{R^{2}} \mathrm{~S}^{2}$ ney Siegel, 1988:238) dengan rumus sebagai berikut: 
HASIL PENELITIAN DAN lapangan, maka masing-masing PEMBAHASAN

Penelitian ini dilakukan pada

Dinas Pendidikan dan Kebudayaan

Kota Banjarmasin. Lembaga

tersebut merupakan unsur

pelaksana pemerintah yang

langsung berada di bawah dan

bertanggung jawab kepada

Walikota Banjarmasin.

Adapun kedudukan, tugas pokok dan fungsi Dinas Pendidikan dan Kebudayaan Pemerintah Kota Banjarmasin secara garis besar dapat dijelaskan sebagai berikut:

Dinas Pendidikan dan Kebudayaan merupakan unsur pelaksana Pemerintah Kota dibidang Pendidikan yang berada dibawah dan bertanggung jawab kepada Walikota melalui Sekretaris Daerah. Dinas dipimpin oleh seorang Kepala

Dinas dan atau dapat dibantu oleh Wakil Kepala Dinas.

\section{Penyajian Data}

Berdasarkan hasil pengolahan data yang diperoleh di variabel dapat dijelaskan sebagai berikut:

a. Struktur Organisasi

Pada variabel struktur organisasi yang diukur berdasarkan pembagian pekerjaan, desentralisasi kewenangan, formalisasi dan koordinasi, dari data yang diperoleh di lapangan.

b. Analisis efektivitas kerja

Pada variabel efektivitas kerja diukur melalui 3 indikator, yaitu produktivitas kerja, efisiensi, dan kepuasan. Untuk mengetahui tingkat efektivitas kerja pegawai pada Dinas Pendidikan dan Kebudayaan di Kota Banjarmasin dapat dilihat pada data sampel yang telah dikemukakan sebelumnya.

\section{Pengujian Hipotesis}

Pada bab sebelumnya dijelaskan, bahwa untuk pengaruh struktur organisasi dengan 
efektivitas kerja pegawai akan selisih nilai $\mathrm{X}$ dengan $\mathrm{Y}$ dan nilai digunakan Uji Statistik Koefisien keseluruhan dari jumlah kuadrat. Korelasi Rank Spearman. Sebelum Langkah selanjutnya adalah masuk kepada rumusan tersebut mencari banyaknya nilai observasi terlebih dahulu dibuat tabulasi nilai $\quad X$ dau $Y$ yang berangka sama, yang secata kumulatif meliputi nilai dengan rumus sebagai berikut: baku $X$ dan $Y$, nilai rank $X$ dan $Y$,

$$
\begin{array}{ll}
\mathrm{t}_{\mathrm{x}} \quad & =\left(2^{3}-2\right)+\left(4^{3}-4\right)+\left(3^{3}-3\right)+\left(3^{3}-3\right)+\left(2^{3}-2\right)+\left(2^{3}-2\right)+\left(2^{3}-2\right) \\
& =6+60+24+24+24+6+6+6 \\
& =156 \\
\mathrm{t}_{\mathrm{y}} & =\left(3^{3}-3\right)+\left(2^{3}-2\right)+\left(4^{3}-4\right)+\left(3^{3}-3\right)+\left(4^{4}-4\right)+\left(2^{3}-2\right) \\
& =24+6+60+24+60+6 \\
& =180
\end{array}
$$

Setelah diketahui nilai

observasi $\mathrm{X}$ dan $\mathrm{Y}$, langkah selanjutnya mencari nilai $\Sigma X^{2}$ atau jumlah skor observasi untuk $X$, dan $\mathrm{y}^{2}$ atau jumlah skor observasi untuk $\Sigma Y$, dengan rumus sebagai berikut:

$$
\begin{aligned}
\sum X^{2} & =\frac{N^{3}-N-\sum T_{x}}{12} \\
= & \frac{34^{3}-34-156}{12} \\
= & \frac{38304-34-156}{12} \\
= & \frac{38214}{12} \\
\sum Y^{2}= & \underline{35} \underline{\mathrm{N}^{3}}-\mathrm{N}-\sum \mathrm{T}_{\mathrm{y}} \\
& =\frac{34^{3}-34-180}{12} \\
& =\frac{38304-34-180}{12} \\
& =38190: 12 \\
& =3176
\end{aligned}
$$

Setelah diketahui nilai $\Sigma X^{2}$ dan $\Sigma Y^{2}$, selanjutnya akan dilakukan perhitungan dengan Uji Statistik Koefisien Korelasi Rank Spearman.

Berdasarkan hasil perhitungan menunjukkan bahwa $\mathrm{r}_{\mathrm{s}}$ hitung sebesar 0,612, jika nilai tersebut dihubungkan dengan nilai harga kritik untuk $n=34$ dan $\alpha=$ 0,05 yaitu sebesar 0,251 berarti $r_{s}$ hitung $\left(0,612>r_{s}\right.$ tabel 0,251). Berarti terdapat hubungan positif antara struktur organisasi dengan 
efektivitas kerja pegawai di Dinas Pendidikan dan Kebudayaan Pemerintah Kota Banjarmasin.

\section{Pembahasan}

Berdasarkan hasil analisis dan pengujian hipotesis, menunjukkan bahwa efektivitas kerja pegawai di Dinas Pendidikan dan Kebudayaan Kota Banjarmasin belum dapat dicapai secara maksimal. Hal tersebut merupakan hasil refleksi dari penerapkan struktur organisasi yang kurang optimal. Efektivitas kerja di lembaga tersebut termasuk dalam katagori cukup baik. Sementara penerapan terhadap struktur organisasi di lembaga tersebut belum sepenuhnya dapat dilaksanakan sesuai kualifikasi parameter yang diukur. Hal tersebut dapat dilihat dari pembagian pekerjaan yang kurang proporsional dan profesional, sehingga berdampak terhadap hasil kerja yang kurang efektif. Terdapat 14,29\% responden menyatakan bahwa pembagian pekerjaan kurang memenuhi standar kualifikasi, sehingga terkesan kurang mendorong motivasi pegawai ke arah hasil kerja yang lebih baik.

Pentingnya

penerapan

prinsip desentralisasi kewenangan dalam suatu organisasi guna mewujudkan hasil kerja suatu organisasi secara efektif telah banyak dikupas, oleh karena itu untuk mendapatkan hasil yang optimum perlu diterapkan secara proporsional.

Selanjutnya mengenai formalisasi, dari hasil pengolahan data menunjukkan bahwa pendapat responden $67,86 \%$ menyatakan cukup baik, hal ini disebabkan para personil dalam menjalankan berbagai aktivitas tidak terlalu banyak diatur dengan berbagai prosedur dan peraturan-peraturan resmi organisasi secara ketat

Selanjutnya dalam hal koordinasi, dari hasil pengolahan data menunjukkan 53,57\%, 
menyatakan bahwa koordinasi yang dilakukan lembaga dalam kaitannya dengan kegiatan lembaga cukup baik. Walaupun demikian koordinasi diupayakan dapat dilaksanakan secara maksimal, sehingga output yang diharapkan dapat direaliasikan dengan baik.

Dalam kaitannya dengan variabel efektivitas kerja, dapat dilihat dari segi kepuasan. Nampaknya terdapat sebagian kecil pegawai yang menyatakan kurang baik, yaitu 10,71 \%. Walaupun jumlah tersebut tidak terlalu berpengaruh banyak terhadap efektivitas organisasi, tetapi dalam efektivitas kerja pegawai cukup menjadi ganjalan dalam memperoleh keluaran secara optimal.

\section{KESIMPULAN DAN SARAN}

\section{Kesimpulan}

1. Berdasarkan hasil penelitian menunjukkan bahwa struktur organisasi mempunyai hubungan positif dengan efektifitas kerja pegawai, khususnya di Dinas Pendidikan dan Kebudayaan Kota Banjarmasin. Hal tersebut didukung hasil uji statistik koefisien korelasi rank Spearman, bahwa $\mathrm{r}_{\mathrm{s}}$ hitung $(0,612)>r_{s}$ tabel $(0,251)$ untuk $n=34$ dan $\alpha=0,05$. Hubungan tersebut dalam kategori meyakinkan atau hubungan kuat, sedangkan besarnya hubungan adalah $44,36 \%$.

2. Kemudian dari uji sampel menunjukkan, bahwa $\mathrm{t}$ hitung $(3,371)>t$ tabel $(2,326)$ pada $\mathrm{n}-2$ dan $\alpha=0,05$. Ini artinya jumlah sampel sebesar 34 orang dari keseluruhan populasi secara representatif dapat mewakili keseluruhan populasi dan hipotesis yang diajukan dapat diterima. Dengan kata 
lain jika struktur organisasi dilaksanakan secara baik, maka efektivitas kerja pegawai akan lebih baik.

3. Hasil analisis data menunjukkan bahwa tingkat efektivitas kerja pegawai di Kantor Pendidikan dan Kebudayaan Kota Banjarmasin termasuk kriteria cukup baik. Hal tersebut merupakan konsekuensi dari parameter struktur organisasi yang secara implementatif kurang optimal atau dalam kategori cukup baik. Data menunjukkan bahwa pembagian pekerjaan di lembaga tersebut kurang didistribusikan secara proporsional. Karena dari 34 responden diantaranya terdapat $50 \%$ menyatakan pembagian pekerjaan cukup baik, 53,57 \% menyatakan desentralisasi kewenangan cukup baik, 67,86 \% menyatakan formalisasi yang menyangkut prosedur kerja cukup baik dan 51,57 \% menyatakan koordinasi yang bersifaf vertikal maupun horisontal cukup baik.

4. Efektivitas kerja pegawai khususnya di Dinas Pendidikan dan Kebudayaan Kota Banjarmasin masih belum menunjukkan hasil yang optimal. Hal tersebut dapat dilihat dari dimensi produktivitas kerja cukup baik, 57,14 menyatakan desentralisasi wewenang, cukup baik, dan 60,72 \% menyatakan pekerjaan yang dihasilkan pegawai cukup memuaskan.

5. Pembagian pekerjaan kurang didasarkan pada kualifikasi pekerjaan, beban kerja volume pekerjaan, kemampuan pegawai, latar belakang pendidikan dan 
tanggung jawab yang harus dipikul oleh pegawai yang bersangkutan.

6. Sebagian besar pegawai yang kurang memahami tugas dan fungsi yang diatur dalam struktur organisasi, kurang mengacu terhadap uraian tugas dan bekerja hanya menunggu perintah atasan, walaupun pekerjaan tersebut tidak termuat dalam uraian tugas. Bekerja mengutamakan kerjasama yang bersifat tambal sulam.

\section{Saran-Saran}

1. Pembagian pekerjaan organisasi harus dilaksanakan, dan perlu didasarkan atas standar kualifikasi pegawai. Pembagian hendaknya didistribusikan secara merata sesuatu dengan uraikan kerja yang sudah diatur menurut peraturan yang berlaku.
2. Pembagian pekerjaan perlu dialokasikan sesuai dengan kemampuan pegawai, dan mempertirnbangkan azas adil dan merata sehingga tidak mengundang munculnya kesan yang egosentris.

3. Untuk pekerjaan yang bersifat rutinitas dan layak untuk dikerjakan eselon bawah hendaknya didesentralisasi kepada pegawai yang dianggap mampu menangani pekerjaan tersebut, sehiingga tidak terkesan sentralistik.

4. Sifat pimpinan paternalistik yang dianggap sebagai penghambat dalam aktivitas organisasi bukan jamannya untuk dipertahankan dan lebih mengutamakan cara-cara yang bersifat demokratis. Karena keterlibatan bawahan dalam pengambilan keputusan merupakan asset organisasi yang perlu dikembangkan sehingga akan terjalin hubungan antara 
bawahan dan atasan lebih kondosif dan akan terciptanya iklim kerja sama yang saling menunjang.

5. Disarankan untuk menerapkan manajemen terbuka, karena dengan manajemen terbuka dapat mendorong motivasi kerja dan meningkatkan partisipasi anggota ke arah tujuan yang telah ditentukan.

6. Dalam rangka untuk meningkatkan efektivitas kerja pegawai, maka secara implementatif elemen-elemen yang terkandung dalam struktur organisasi, baik menyangkut pembagian pekerjaan, desentralisasi kewenangan, formalisasi, dan koordinasi hendaknya harus diaplikasikan secara proporsional.

\section{DAFTAR PUSTAKA}

Anonim, 1990, Keputusan Menteri Pendayagunaan Aparatur Negara No. 19 Tahun 1990, tentang Kerangka Pemacu, Program Pemacu
Pendayagunaan Aparatur Negara, Republik Indonesia.

Gibson, Ivancevich Donnelly. 2007, Organisasi dan Manajemen, Perilaku, Struktur, Proses, "Erlangga" Jakarta.

Hasibuan, M.S.P. 2004, Manajemen Sumber Daya Manusia, Dasar dan Kunci Keberhasilan. Haji Masagung. Jakarta.

Islamy, Irfan. 1991. Prinsip-prinsip Perumusan Kebijakan Negara. Bumi Aksara. Jakarta.

Ishak, 2002, Hubungan Struktur Organisasi Dengan Efektifitas Kerja Pegawai, Studi Kasus Di Kantor Dinas Pendidikan Nasional Kabupaten Pasir, Tesis, Unibraw, Malang.

Noe, et.al (2006), HRM : Gainning a Competitive Advantage, Third Edition, USA.

Simamora (2004), Manajemen Sumber Daya Manusia, STIE-YPKN, Jakarta.

Singarimbun, M \& Effendi, S (2004), Metode Penelitian Survey, LP3ES, Jakarta. 
Sugiono, 2006, Metode Penelitian Bisnis, Penerbit Rineka Pustaka, Jakarta.

Yamane, 1989, Metode Penelitian Komunikasi. Diterjemahkan
Jalaluddin Rahkmat, Remaja Karya. Bandung. 